\title{
SOLID-MATRIX LUMINESCENCE ANALYSIS
}

\section{Progress Report}

Period of Grant: 15 June 92 - 14 June 95

Period of Report: 1 November 91 - 15 January 93

\author{
R. J. Hurtubise
}

Chemistry Department

University of Wyoming

Laramie, WY 82071-3838

Prepared for the U.S. Department of Energy

Agreement No. DE-FG02-86ER13547

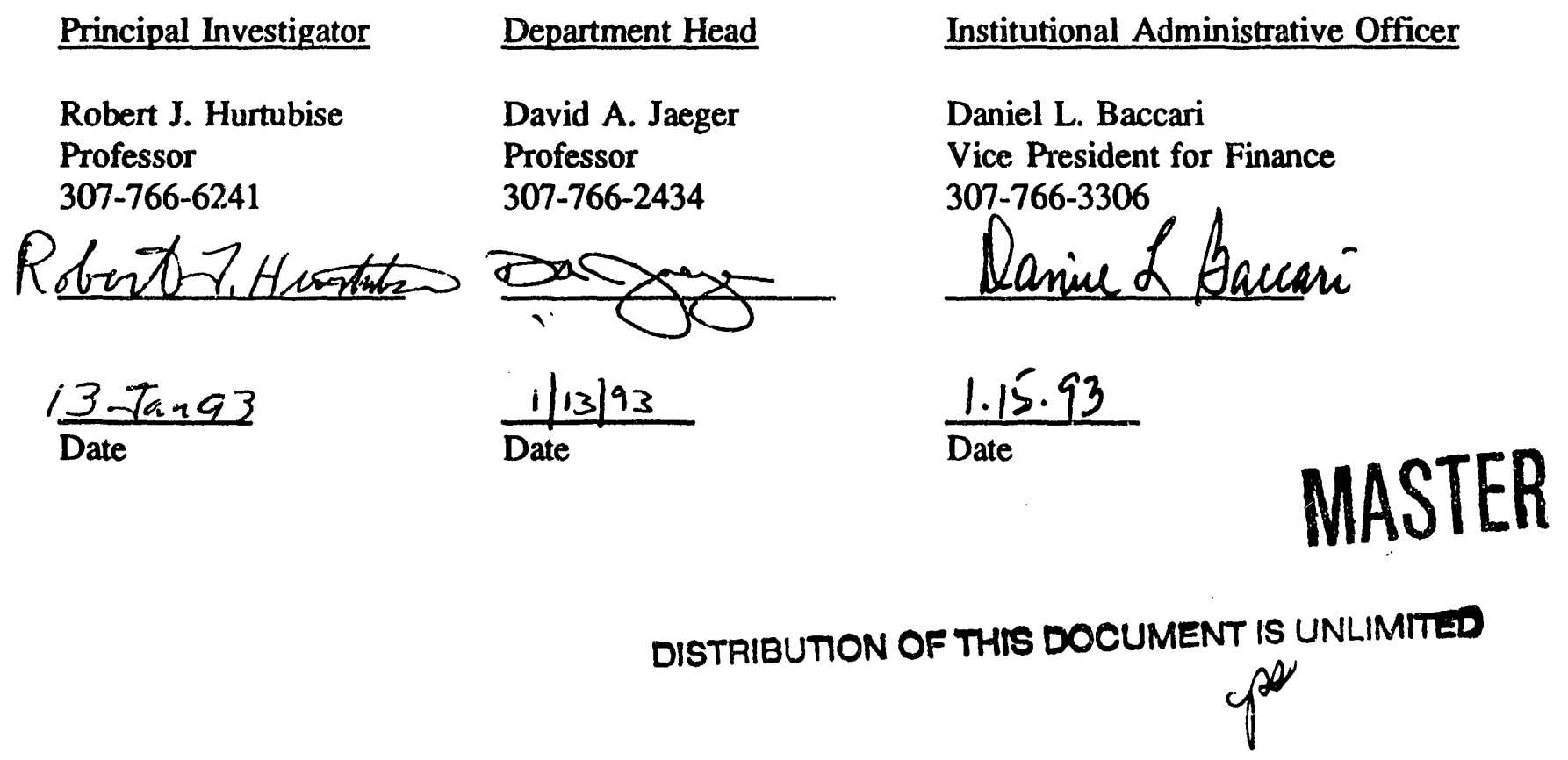




\section{- $\underline{\text { Summary }}$}

Several interactions with lumiphors adsorbed on filter paper were elucidated from experiments with moisture, modulus and heavy-atom salts. The data were interpreted using static and dynamic quenching models, heavy-atom theory, and a theory related to the modulus of paper. With cyclodextrin-salt matrices, it was shown that $10 \% \alpha$-cyclodextrin $/ \mathrm{NaCl}$ was very effective for obtaining strong room-temperature fluorescence and moderate room-temperature phosphorescence from adsorbed stereoisomeric tetrols. Extensive photophysical information was obtained for the four tetrols on $10 \% \alpha$-cyclodextrin $/ \mathrm{NaCl}$. The photophysical information acquired was used to develop a method for characterizing two of the tetrols. Work with model compounds adsorbed on deuterated sodium acetate showed that $\mathrm{C}-\mathrm{H}$ vibrations in the undeuterated sodium acetate were not responsible for the deactivation of the excited triplet state in the model phosphors investigated. A considerable amount of solution luminescence and solidmatrix luminescence data were compared. The most important finding was that in several cases the room-temperature solid-matrix luminescence quantum yields were greater than the solution low-temperature quantum yield values.

\section{DISCLAIMER}

This report was prepared as an account of work sponsored by an agency of the United States Government. Neither the United States Government nor any agency thereof, nor any of their employees, makes any warranty, express or implied, or assumes any legal lisibility or responsibility for the accuracy, completeness, or usefulness of any information, apparatus, product, or process disclosed, or represents that its use would not infringe privately owned rights. Reference herein to any specific commercial product, process, or service by trade name, trademark, manufacturer, or otherwise does not necessarily constitute or imply its endorsement, recommendation, or favoring by the United States Government or any agency thereof. The views and opinions of authors expressed herein do not necessarily state or reflect those of the United States Government or any agency thereof. $\therefore$ CEVEO

meY 13153

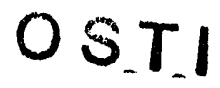




\section{A. Introduction}

In this report, the major results and conclusions of the research over the past fourteen months of the research will be presented. Work has centered around physicochemical interactions, new solid matrices, and analytical figures of merit in solid-matrix luminescence.

\section{B. Interactions in Filter Paper}

In continuing our experiments with the effects of moisture on the room-temperature fluorescence (RTF) and the room-temperature phosphorescence (RTP) of aromatic compounds adsorbed on filter paper, we recently reported on the mechanistic aspects of moisture quenching in solid-matrix luminescence with phenylphenols (1). Several things were learned from this study. The two most important aspects discovered were that the changes in the phosphorescence intensities were related to the changes in the modulus of filter paper as the humidity increased, and phosphorescence lifetimes were not affected much by the increase in the humidity. Static and dynamic quenching models from solution luminescence theory were used to interpret the luminescence data. This part of the project showed that solution luminescence theory will have to be modified to mere fully explain the solid-matrix luminescence data.

In experiments related to the discussion in the above paragraph, the modulus of filter paper was obtained as a function of humidity with equipment in the Mechanical Engineering Department at the University of Wyoming. In addition, the adsorption isotherms were obtained for moisture uptake on filter paper under several experimental conditions. The modulus data and isotherm data will be correlated with solid-matrix luminescence data and then related to Nissan's model which describes the change in the modulus of filter paper with adsorbed moisture (2).

A rather extensive study was carried out on the photophysical properties resulting from the heavy-atom effect in solid-matrix luminescence using 4-phenylphenol as a model compound 
(3). This was the first detailed work reported in the literature on the photophysical parameters related to the heavy-atom effect in solid-matrix luminescence. Also, the increase in phosphorescence lifetime for 4-phenylphenol from room temperature to low temperature was shown to be related to the increase in the Young's modulus of filter paper as the temperature was lowered. Calculated phosphorescence lifetimes at room temperature and at low temperature, using equations that included Young's modulus values, agreed very well with experimental lifetime values (3).

\section{Cyclodextrins}

Experiments were carried out to determine the best solid-matrix luminescence conditions with $\alpha-, \beta-$, and $\gamma$-cyclodextrin/salt matrices for the four stereoisomers of the tetrols (4). Tetrols are hydrolysis products from benzo(a)pyrene-DNA adducts. It was found that with $10 \%$ $\alpha$-cyclodextrin $/ \mathrm{NaCl}$ the tetrols gave strong RTF and moderately strong RTP. A typical limit of detection for the tetrols was 62 femtomoles/mg with RTF and 94 femtomoles/mg with RTP. Recent experiments have shown that the limits of detection of the tetrols can be improved considerably by using a heavy atom in the solid matrix.

In relationship to the work described in the paragraph above, an extensive study was carried out on the solid-matrix luminescence photophysical properties of the tetrols adsorbed on $10 \% \alpha$-cyclodextrin $/ \mathrm{NaCl}$ (5). Several luminescence quantum yields, luminescence lifetimes, and photophysical rate constants were acquired. An important conclusion from this part of the research, was that the even though the tetrols are stereoisomers there structures are different enough so that some of there Iriminescence parameters are not the same. Also, a method was developed for distinguishing two of the tetrols by their solid-matrix luminescence properties. For example, comparison of the rates constants for intersystem crossing from the excited singlet state 
to.the excited triplet state showed that the values of the constants were very different for the two tetrols.

In work related to the solution fluorescence properties of model compounds interacting with $\beta$-cyclodextrin, the fluorescence properties of 1-naphthol, 2-naphthol, and 1,2,3,4-tetrahydronaphthol were studied in aqueous alcohol solvents containing $\beta$-cyclodextrin (6). These studies were undertaken because the solution chemistry related to solid-matrix luminescence has not been studied in detail. The fluorescence of both the molecular and anionic forms of 1-naphthol and 2-naphthol were observed in the binary solvents without $\beta$-cyclodextrin. Also, the fluorescence intensity of 1,2,3,4-tetrahydronaphthol decreased with an increase in the amount of $\beta$-cyclodextrin. The fluorescence results were interpreted with the Stern-Volmer equation and a modified Stern-Volmer equation. It is emphasized that solution interaction studies will not be undertaken in detail because the most important interactions occur in the solid matrix.

\section{Sodium Acetate}

Work is continuing with sodium acetate to study the fundamental interactions of lumiphors adsorbed on this material. Sodium acetate serves as a model solid matrix because its structure is known and the understanding gained from sodium acetate can be used to elucidate interactions with other solid matrices (7). Recently, we compared luminescence intensities and phosphorescence lifetimes for three model compounds adsorbed on sodium acetate and deuterated sodium acetate. The data revealed that the $\mathrm{C}-\mathrm{H}$ vibrations in sodium acetate are not responsible for the nonradiative loss of energy from the triplet state. In addition, the results have shown that the solid matrix plays a very important role in determining the phosphorescence properties of the adsorbed phosphor.

In other experiments, samples of sodium acetate and sodium acetate $\mathrm{NaCl}$ mixtures were 
sent to Dr. Juliana Boerio-Goates of Brigham Young University for heat capacity analysis. The heat capacity of these samples will be obtained in increments from room temperature to about $90 \mathrm{~K}$. Also, the heat capacity will be obtained on a sample of $30 \% \beta$-cyclodextrin $/ \mathrm{NaCl}$ over the same temperature range. The heat capacity results will be correlated with photophysical data obtained earlier from model compounds adsorbed on these solid matrices.

\section{E. Other Solid-Matrix Luminescence Results}

A manuscript was recently accepted for publication in which we compare a very large amount of solution and solid-matrix luminescence parameters (8). This is an important paper because it is the first time that comparisons have been made for both room-temperature and lowtemperature fluorescence and phosphorescence quantum yields, fluorescence and phosphorescence lifetimes, and several photophysical rate constants obtained from solution and solid-matrix data. One of the most important results was that, in many, cases solid-matrix luminescence can give greater fluorescence and phosphorescence quantum yields at room temperature compared to the corresponding solution quantum yields at low temperature.

An equation that relates the ratio of fluorescence to phosphorescence quantum yields as a function of temperature to basic photophysical parameters was developed (9). 'The quantum yield data were obtained from three compounds on three different solid matrices. For some systems, the quantum yield ratio was only a function of phosphorescence lifetime as the temperature was lowered. However, with other systems, the quantum yield ratio was a function of phosphorescence lifetime and the rate constant of intersystem crossing from the excited singlet state to the excited triplet state. 'The equation is an important one because it defines in a rather simple fashion the fundamental parameters that cause the luminescence quantum yield ratio to change as temperature is lowered. 


\section{F. . Other Experiments}

The new Perkin-Elmer LS-50B arrived and was set up by a Perkin-Elmer representative. Most features of the instrument are working well, but a considerable amount of time was spent in checking the procedure for determining quantum yield values. Presently, the LS-50B gives high solution quantum yield values. The problem has been discussed with several Perkin-Elmer representatives, but they have no explanation for the high values. Work is continuing to solve the problem.

\section{Literature Cited}

1. Purdy, B.B.; Hurtubise, R.J. Anal. Chem. 1992, 64, 1400, "Mechanistic Aspects of Moisture Quenching in Solid-Matrix Luminescence with Phenylphenols Adsorbed on Filter Paper."

2. Batten, G.L.; Nissan, A.H. Tappi, 1987, 70, 119, Unified Theory of the Mechanical Properties of Paper and Other H-Bond-Dominated Solids-Parts I."

3. Purdy, B.B.; Hurtubise, R.J. Appl. Spectrosc. 1992, 46, 988, "Changes in the Photophysical Properties with Heavy Atoms and the Effects of Modulus for 4-Phenylphenol in Solid-Matrix Luminescence."

4. Corley, J.S.; Hurtubise, R.J. Anal. Lett. 1992, 25, 1559, Luminescence Properties and Analytical Figures of Merit of the Tetrols of Benzo(a)Pyrene-DNA Adducts Adsorbed on $\alpha$-, $\beta$ - and $\gamma$-Cyclodentrin $/ \mathrm{NaCl}$ Mixtures."

5. Corley, J.S.; Hurtubise, R.J. Anal. Chem., to be submitted, "Solid-Matrix and Solution Luminescence Photophysical Parameters and Analytical Aspects of the Tetrols of Benzo(a)Pyrene-DNA Adducts."

6. Wu, D.; Hurtubise, R.J. Talanta, in press, "Fluorescence Properties of 1-Naphthol, 2-Naphthol, and 1,2,3,4-Tetrahydronaphthol in Aqueous Alcohol Solvents with and without $\beta$-Cyclodextrin."

7. Ramasamy, S.M.; Hurtubise, R.J. Anal. Chem., 1990, 62, 1060, "Comparative Study of Solid-Matrix Luminescence Interactions of p-Aminobenzoate on Two Different Matrices."

8. Hurtubise, R.J.; Ramasamy, S.M. Appl. Spectrosc., in press, "Comparison of Solution and Solid-Matrix Luminescence Parameters." 
9. Hurtubise, R.J.; Ramasamy, S.M. Appl. Spectrosc., in press, "Comparison of Fluorescence-to-Phosphorescence Quantum Yield Ratios in Solid-Matrix Luminescence as a Function of Temperature." 
A. The Following Manuscripts Were Listed as "In Review" or "In Press" in the Last Progress Report (Period of Report: 15 June 89 to 31 October 91)

1. Citta, L.A.; Hurtubise, R.J. Talanta, 1992, 39, 1065," Analytical and Mechanistic Aspects of the Room-Temperature Fluorescence and Phosphorescence of Benzo(f)quinoline Adsorbed on Silica Gel Chromatoplates with Humidified Gases."

2. Ramasamy, S.M.; Hurtubise, R.J. Appl. Spectrosc., 1992, 46, 472, "Solid-Matrix Luminescence Polarization of p-Aminobenzoate Adsorbed on Sodium Acetate and Sodium Acetate/Sodium Chloride Mixtures."

3. Citta, L.A.; Hurtubise, R.J. Appl. Spectrosc., 1991, 45, 1547, "The Effects of Moisture and Gases on the Room-Temperature Fluorescence and Phosphorescence of Model Aromatic Compounds Adsorbed on Filter Paper."

4. Purdy, B.B.; Hurtubise, R.J. Anal. Chim. Acta, 1992, 257, 139, "Effects of Salts on the Solid-Matrix Luminescence of Phenylphenol Isomers Adsorbed on Filter Paper."

5. Richmond, M.D.; Hurtubise, R.J. Anal. Chim. Acta, 1991, 255, 335, "ß-Cyclodextrin Solid-Matrix Luminescence Characterization of Stereoisomeric Tetrols."

B. The Following Manuscripts Have Resulted Since the Last Progress Report and Cover the Latest Report (Period of the Report: 1 November 91 to 15 January 93)

1. Purdy, B.B.; Hurtubise, R.J. Anal. Chem. 199.2, 64, 1400, "Mechanistic Aspects of Moisture Quenching in Solid-Matrix Luminescence with Phenylphenols Adsorbed on Filter Paper."

2. Purdy, B.B.; Hurtubise, R.J. Appl. Spectrosc. 1992, 46, 988, "Changes in the Photophysical Properties with Heavy Atoms and the Effects of Modulus for 4-Phenylphenol in Solid-Matrix Luminescence."

3. Corley, J.S.; Hurtubise, R.J. Anal. Lett. 1992, 25, 1559, Luminescence Properties and Analytical Figures of Merit of the Tetrols of Benzo(a)Pyrene-DNA Adducts Adsorbed on $\alpha$-, $\beta$ - and $\gamma$-Cyclodextrin $/ \mathrm{NaCl}$ Mixtures."

4. Corley, J.S.; Hurtubise, R.J. Anal. Chem., in review, "Solid-Matrix and Solution Luminescence Photophysical Parameters and Analytical Aspects of the Tetrols of Benzo(a)Pyrene-DNA Adducts."

6. Wu, D.; Hurtubise, R.J. Talanta, in press, "Fluorescence Properties of 1-Naphthol, 2-Naphthol, and 1,2,3,4-Tetrahydronaphthol in Aqueous Alcohol Solvents with and without $\beta$-Cyclodextrin." 
7. Hurtubise, R.J.; Ramasamy, S.M. Appl. Spectrosc., in press, "Comparison of Solution and Solid-Matrix Luminescence Parameters."

8. Hurtubise, R.J.; Ramasamy, S.M. Appl. Spectrosc., in press, "Comparison of Fluorescence-to-Phosphorescence Quantum Yield Ratios in Solid-Matrix Luminescence as a Function of Temperature."

9. Hurtubise, R.J. "Solid-Phase Luminescence Spectroscopy" for the Encyclopedia of Analytical Science to be published by Academic Press Limited. The previous manuscript considers some the research results obtained under DOE funding. 

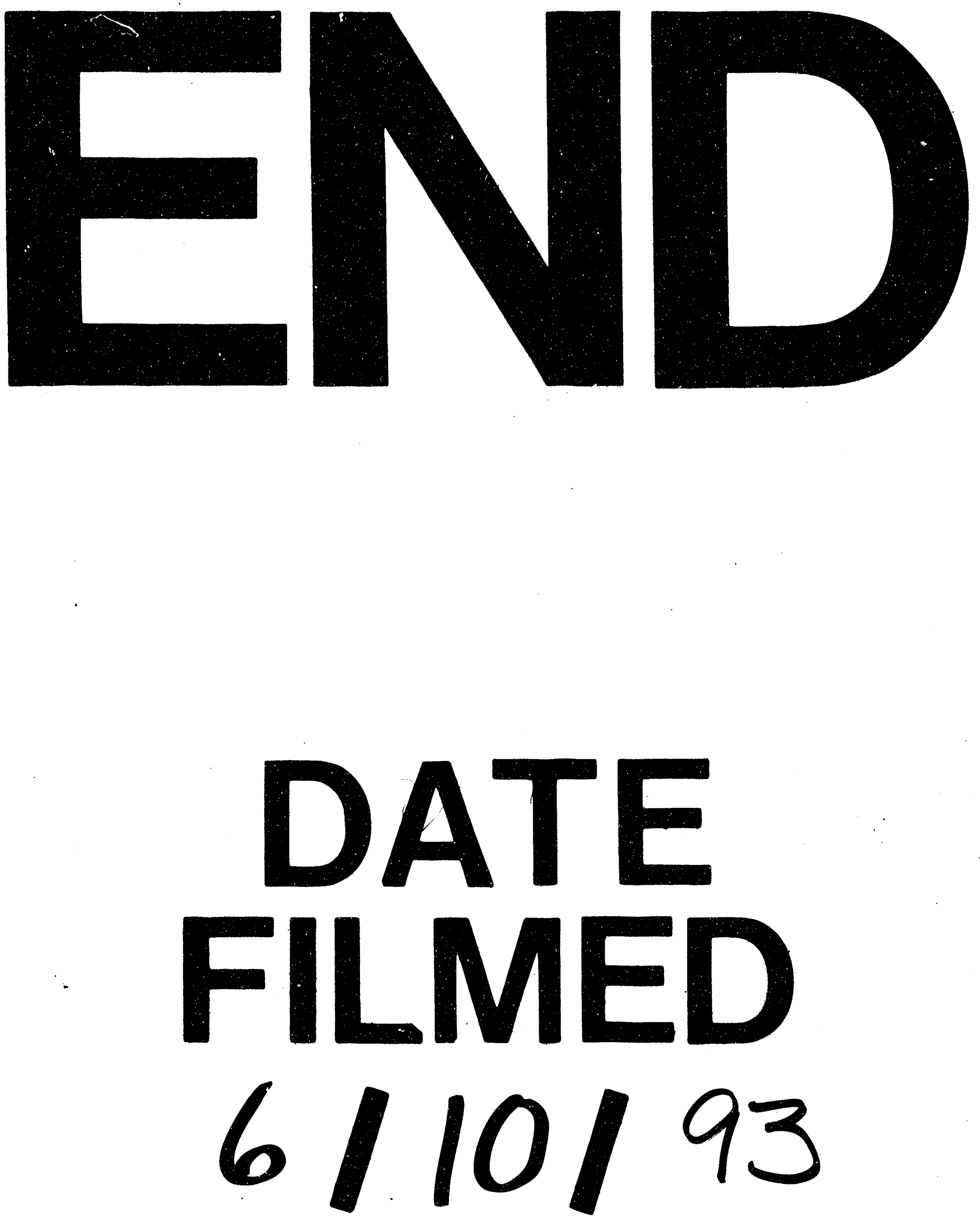
